\title{
Urdimento
}

Revista de Estudos em Artes Cênicas

E-ISSN: 2358.6958

\section{A concepção de Cenografia que cria diferentes conexões entre edifício teatral e cidade}

\author{
Regilan Deusamar Barbosa Pereira
}

\section{Para citar este artigo:}

PEREIRA, Regilan Deusamar Barbosa. A concepção de Cenografia que cria diferentes conexões entre edifício teatral e cidade. Urdimento, Florianópolis, v. 2, n. 38, ago./set. 2020.

DOI: http:/dx.doi.org/10.5965/14145731023820200020

Este artigo passou pelo Plagiarism Detection Software | iThenticate 


\title{
A concepção de Cenografia que cria diferentes conexões entre edifício teatral e cidade
}

\author{
Regilan Deusamar Barbosa Pereira ${ }^{1}$
}

\begin{abstract}
Resumo
O edifício teatral constrói relações profissionais e humanas, as quais desenvolvem singular trânsito entre este edifício e a cidade que o abriga. Esta perspectiva proporcionou um singular conceito de Cenografia. A fundamentação teórica está centrada no estudo epistemológico que Michel Foucault empreendeu, ao reconhecer no século XVI a ação cognitiva de "espacializar o conhecimento", a qual conecta o microcosmo ao macrocosmo. Este "espacializar" cognitivo será considerado de acordo com os espaços físico e virtual. O virtual será analisado a partir da plataforma digital, que permite que performance teatral e plateia se encontrem em ruas e praças, recriando as normas de confinamento.
\end{abstract}

Palavras-chave: Edifício Teatral. Cidade. Espaço Físico. Espaço Virtual.

\section{The design of scenography that creates different connections between theatrical building and city}

\begin{abstract}
The theater building builds professional and human relationships, which develop a unique transit between this building and the city that houses it. This perspective provided a unique concept of Scenography. The theoretical foundation is centered on the epistemological study that Michel Foucault undertook, recognizing in the 16th century the cognitive action of "spatializing knowledge", which connects the microcosm to the macrocosm. This cognitive "spatialization" will be considered according to the physical and virtual spaces. The virtual will be analyzed using the digital platform, which allows theatrical performances and audiences to be found in streets and squares recreating the containment rules.
\end{abstract}

Keywords: Theater Building. City. Physical Space. Virtual Space.

${ }^{1}$ Cenógrafa e figurinista, doutora pelo Programa de Pós Graduação em Artes Cênicas da Universidade Federal do Estado do Rio de Janeiro - UNIRIO, e integrante do Laboratório de Estudos do Espaço Teatral e da Memória Urbana desta mesma universidade. Professora Substituta no Curso de Teatro da Universidade Federal de São João del Rei (UFSJ), onde leciono as disciplinas de Cenografia e Indumentária. regilandeusamar@gmail.com 


\section{A Cidade apropriada pela Poética da Cenografia}

Aquele coreto, na região central da praça trazia à memória reuniões festivas, primaveris, encontros entre famílias residentes em localidades próximas, acalentadas por bandas musicais. No entanto esta era uma memória imaginada por mente estrangeira, que nalguma fotografia, exposição museológica teve a oportunidade de se conectar com tempos passados, e a partir de então recriar os acontecimentos naquele distinto coreto no centro da praça. Mas a grande oportunidade imaginativa foi alçada pelo convite para adentrar e conhecer aquele patamar superior: admirar a cidade do ponto de vista da banda de músicos. O guia turístico gentilmente conduziu aquela oportunidade inesperada, mas suas narrações históricas ficaram esquecidas no tempo. Ao longe, a visão do teatro da cidade era mais interessante. O córrego se fazia imponente, parecia murmurar segredos do tempo, as palmeiras verdejavam a paisagem com intensidade. Contrastando com a poesia e a natureza, a estação ferroviária evidenciava a máquina, para que a imaginação não esquecesse que a tecnologia de motores, bem como a de comunicação, inevitavelmente nos contaminaria. E a memória imaginativa subitamente se vestiu de realidade: neste espaço habita a humanidade, que aprimora a vida em sociedade através da arte e da cultura.

Os monumentos arquitetônicos que constituem os espaços urbanos, aliados à geografia local e respectivos espaços de natureza, configuram conjuntamente tanto os valores destacados pela sociedade quanto as feições estéticas, a manutenção de formas, cores, memórias que vivificam as cenas urbanas, escritas culturais traduzidas em fachadas das edificações, monumentos escultóricos em distintos espaços da cidade que exaltam personalidades da história, da mitologia local, ou ainda valorização das riquezas naturais. Esta cenografia urbana se constitui como farto material de estudo que promove não somente uma potente aliança com a cenografia endereçada aos edifícios teatrais, mas promove também formação e atuação cidadã, pois o objetivo é o de estender a consciência de construção do espaço teatral aos valores estruturais edificados pelos interesses de diferentes sociedades urbanas. 
O cenógrafo e professor Helio Eichbauer, em sua conferência intitulada $A$ musa urbana - os coretos da cidade, realizada em agosto de 2014 na 2a Jornada Nacional Arquitetura, Teatro e Cultura, organizada conjuntamente pelo Laboratório de Estudos do Espaço Teatral e Memória Urbana e UNIRIO, destacou a importância dos coretos para a produção artística e cultural das cidades. Suas palavras evidenciam distintos e importantes fatores e valores:

Os coretos construídos para apresentações de bandas de música pulsavam como o coração da praça, espaço urbano democrático e congregador. Inúmeros exemplos dessas notáveis construções devem ser revisitados e alguns restaurados urgentemente nas cidades brasileiras, assim como as festas nas praças, com música e arrasta-pé! Nós que vivemos entre projetos urbanos arrojados e ruínas, entre a utopia e o desmantelo. Alô Penha, Méier, Vigário Geral, Quintino, Sepetiba, Niterói! Salve Anacleto de Medeiros e a banda do Corpo de Bombeiros do Rio de Janeiro desde 1896! (Eichbauer, 2014, p. 46).

Ao definir o coreto como o coração da praça, o lugar de lazer e reunião social das cidades, o cenógrafo Eichbauer distingue este monumento arquitetônico como potente órgão social, que vivifica as relações humanas através da arte, da música, como musa inspiradora, "musa urbana". Este modo de considerar um monumento da cidade, que analogamente aproxima o corpo humano e a arte condiz com as considerações de Michel Foucault em As palavras e as coisas: uma arqueologia das ciências humanas, na medida em que realiza uma aproximação entre o macrocosmo e o microcosmo, de acordo com uma episteme que busca "espacializar os conhecimentos" (Foucault, 2007, p. 52). Trata-se, portanto, de uma importante aproximação que o projeto em cenografia - linguagem que concebe e empreende o espaço - realiza entre o microcosmo do edifício teatral e o macrocosmo que é a cidade que o abriga. Tal conexão situa o pensar e produzir cenografia entre os edifícios teatrais e o cotidiano das cidades e seus cidadãos e cidadãs.

Diferentemente do desenho arquitetônico e urbanista o projeto cenográfico está livre para empreender formas, cores e texturas em criações que podem reinventar o cotidiano em efêmeras criações ou não. Esta liberdade permite que o projeto cenográfico realize concepções poéticas, quando comparadas às 
necessidades pragmáticas do dia-a-dia, que conectadas aos edifícios teatrais, têm a capacidade de colaborar com uma percepção inventiva dos espaços urbanos, capaz de renovar áreas esmaecidas das cidades com apenas o incentivo de um novo uso daquele espaço. Esta renovação também pode ser promovida através dos cursos de cenografia, os quais considerem visitações às mais diferentes regiões das cidades com o objetivo de aproximar cidade e teatro, empreendendo um estudo do espaço cênico conectado ao estudo do espaço da cidade. Esta forma de conceber o estudo da cenografia tem como fundamento a Pedagogia da autonomia desenvolvida por Paulo Freire:

Por que não estabelecer uma "intimidade" entre os saberes curriculares fundamentais aos alunos e a experiência social que eles têm como indivíduos? Por que não discutir as implicações políticas e ideológicas de um tal descaso dos dominantes pelas áreas pobres da cidade? A ética. [...]. Não é possível também formação docente indiferente à boniteza e à decência que estar no mundo, com o mundo e com os outros substantivamente exige de nós. Não há prática docente verdadeira que não seja ela mesma um ensaio estético e ético. (Freire, 2016, p. 32 e 46).

Esta maneira que Freire concebe a Educação pode encontrar um paralelo nas reflexões de Eichbauer a respeito dos coretos das cidades, conforme um "ensaio estético e ético". De acordo com as reflexões do cenógrafo Helio Eichbauer sobre os coretos, notabilizam-se vários munícipios distintos da capital do Rio de Janeiro, inclusive municípios localizados em regiões que se diferenciam como periféricas, dada a distância da capital, regiões que possuem inferiores condições econômicas e até mesmo distintas culturas, que, no entanto, em comum possuem o coreto, "o coração da praça”, "a musa urbana”, que pode reavivar o contexto cultural e artístico daquelas regiões. A fala de Eichbauer é imperativa a respeito destes espaços: "Inúmeros exemplos dessas notáveis construções devem ser revisitados e alguns restaurados urgentemente", afinal é o coração que precisa pulsar vida e afetividades através da arte no espaço das cidades. Trata-se de reavivar em conjunto com a população os instrumentos de cultura e arte, ocupar estratégicos espaços das cidades com a produção artística local, empreender humanidades através das expressões poéticas, cênicas, musicais, lúdicas que pulsam em busca 
de espaços de expressão e compartilhamento. Tais pulsares estão presentes em todas as comunidades urbanas porque a cultura subsiste entre os agrupamentos humanos. Possivelmente índices alarmantes de violência urbana se destaquem em algumas cidades, mas justamente estes alarmes indicam que a população local necessita reconhecer valores afetivos que estejam mortificados. Justamente os espaços de realização artística comunitária podem promover novos modos de vida, novas realizações sociais que elevem a qualidade de vida local.

\section{O Edifício Teatral apropriado pela Cidade}

Ao buscar "espacializar os conhecimentos", e consequentemente conectar o microcosmo ao macrocosmo, de acordo com os estudos de Foucault, os edifícios teatrais podem pulsar como parte do órgão cerebral das cidades. Conexões entre escolas e teatros devem ser pensadas no sentido da aproximação entre a arte e a educação. Neste processo as diferentes linguagens artísticas que atuam no fazer das artes cênicas podem realizar diferentes projetos, mas a cenografia especificamente pode estender sua atuação criando trajetórias de mão dupla entre a praça e o edifício teatral, do ir e vir entre o cotidiano e o ficcional que promovam espaços de expressão artística, criação de novas realidades a partir da cultura comunitária.

Esta compreensão do edifício teatral como espaço conectado à cidade pela via da Educação foi estudada no artigo A humanidade da caixa cênica italiana de acordo com o discurso do cenógrafo e professor Helio Eichbauer ${ }^{2}$, no qual a existência de uma sala de aula contígua à sala de espetáculos foi considerada como um instrumento promotor da conexão entre ética e estética bem como instrumento de aprimoramento artístico, inclusive aprimoramento dos técnicos como costureiras, carpinteiros, eletricistas que são fundamentais para a produção cênica e funcionamento do maquinário que constitui o edifício teatral, daí a

Este artigo foi publicado nos anais da Abrace, cujos estudos foram principiados no resumo apresentado para a X Reunião Científica desta associação, realizada em 2019, na UNICAMP. O artigo se encontra disponível em https://www.publionline.iar.unicamp.br/index.php/abrace/article/view/4601 
humanidade deste edifício que não somente dialoga com os espectadores, mas também demanda o ofício técnico e artístico de homens e mulheres, construindo consequentemente diálogos no espaço da plateia bem como diálogo no espaço dos bastidores.

Neste espaço vital, onde a construção da cena se produz, o diálogo pode se restringir ao estritamente técnico e funcional, o que impede a plena expansão da vivência artística que este edifício promove. A conexão entre sala de espetáculo e sala de aula no espaço do edifício teatral pode enriquecer a cultura comunitária, bem como trazer para o microcosmo deste edifício "a assunção de nós mesmos por nós mesmos" (Freire, 2016, p. 42) através da apropriação da conexão que existe entre os profissionais que atuam no edifício teatral com o espaço da cidade que abriga o teatro. Esta apropriação pode promover uma vivência artística mais acentuada por parte da população, no sentido de que a comunidade pode não somente apreciar, mas inclusive fazer, experimentar arte nas suas diferentes formas de expressão, seja no interior do edifício teatral seja criando novos espaços de arte e cultura na cidade, de acordo com Freire, assumindo a própria identidade e ocupando os próprios equipamentos culturais. A sala de aula contígua à sala do espetáculo é, portanto, a oportunidade de dialogar artisticamente com a costureira cênica, por exemplo, que mora na região metropolitana que envolve o edifício teatral, oportunidade de dialogar sobre Shakespeare e Nelson Rodrigues em conjunto com atores, figurinistas, eletricistas. Oportunidade de discutir a sociedade através da arte teatral entre técnicos, atores, diretores. Não isoladamente costurar um figurino, ensaiar um personagem, mas conjuntamente toda equipe de construção do espetáculo participar de uma oficina de duas, três aulas sobre o conteúdo da peça, discutir o enredo, participar da construção do pensamento crítico sobre a encenação, considerando que o eletricista que chega ao teatro para montar os refletores traz as vivências de seu bairro de residência, e poderá levar de volta as reflexões que Shakespeare the promoveu na oficina com atores e diretores.

A arquiteta Lina Bo Bardi, entre finais da década de 1950 e início de 1960 teve a oportunidade, ainda que breve, pois seu trabalho foi interrompido pela 
instauração da ditadura militar em 1964, de conectar provisoriamente o Teatro Castro Alves em Salvador ao Museu de Arte Moderna da Bahia ${ }^{3}$, que ainda não tinha uma sede definitiva ${ }^{4}$. No foyer do Teatro Castro Alves, que era a rampa de acesso à plateia deste teatro, o Museu de Arte Moderna da Bahia ficou provisoriamente instalado de 1960 a 1963, quando por ocasião das obras no Castro Alves o Museu foi transferido para o Solar do Unhão, onde se encontra nos atuais dias (Pereira, 2007, p. 116). Neste espaço Lina Bardi promoveu exposições diversas e tratou das temáticas concernentes à Arte Moderna. Bardi tinha o objetivo de fazer uma aproximação entre a população local e esta forma de concepção artística, para que as questões conceituais da Arte Moderna fossem pensadas, vistas e debatidas também pelas classes populares. Esta realização da arquiteta Lina Bardi se estabeleceu em parceria com o então diretor da Escola de Teatro da Universidade da Bahia, Martim Gonçalves. Tal colaboração oportunizou a conexão dos alunos da universidade com o Teatro Castro Alves, promoveu, portanto, prolífica conjunção entre artes visuais, teatro e ainda oficinas de cinema num mesmo espaço. Esta realização traz à nossa contemporaneidade a instigante reflexão de que tal comunhão pode ser ainda mais ampliada através das plataformas midiáticas disponibilizadas no ciberespaço, não obstante a consideração de que a conexão de diferentes linguagens artísticas, plateias e artistas que Lina Bardi e Martim Gonçalves realizaram no Teatro Castro Alves em meados do século XX já se constitui como um empreendimento bastante complexo e vultuoso, que se apresenta como exemplar realização, importante fonte de estudo, que conectou arte com as classes populares:

Povo vai ao Museu: vê modernos, reage, mas sai gostando.

\footnotetext{
A respeito deste período de atuação da arquiteta Lina Bo Bardi, os estudos de Juliano Aparecido Pereira intitulados A ação cultural de Lina Bo Bardi na Bahia e no Nordeste (1958-1964), publicados em 2007, forneceram informações históricas e biográficas da arquiteta Bardi que se constituíram como uma das bases para as considerações pedagógicas no campo da cenografia apresentadas neste artigo.

${ }^{4}$ De acordo com Pereira: "Com relação a este projeto de ação conjunta, há um documento sobre um convênio firmado entre o Estado da Bahia, a Universidade da Bahia e o Museu de Arte Moderna. Neste, lê-se: item VI - O TEATRO CASTRO ALVES servirá como sede de exposições, congressos, conferências, centros de pesquisa, espetáculos teatrais e de cultura cinematográfica, cursos e palcos de filmagem, permanecendo o foyer como galeria do MUSEU DE ARTE MODERNA DA BAHIA; e ainda no item VII - A UNIVERSIDADE DA BAHIA usará as dependências e instalações do TEATRO CASTRO ALVES para ensaios e espetáculos das Escolas de Teatro, Dança e dos Seminários de Música. (Fonte: MAM-BA. Salvador - outubro de 2000)." (Pereira, 2007, p. 153)
} 


\begin{abstract}
-Eu não entendo que mancha é esta. É isto que chamam de arte? [...] -Eu ia ver uma fita de cinema, mas como me disseram que tinha agora Museu de Arte Moderna, resolvi conhecê-lo. Mas não estou entendendo nada o senhor pode me explicar [...] sr.a Lina Bo Bardi ouviu também as queixas do cidadão. Calma, muito calma e solícita, respondeu: [...] O senhor nunca fechou os olhos e viu muitas manchas aparecerem? O senhor nunca sonhou e viu nos sonhos coisas belas, mas sem sentido? -Ah, então quer dizer que isso é arte moderna? Interferiu o cidadão, se entusiasmando [...]. Então a sr.a Lina disse que ele já estava mais esclarecido a respeito do assunto.

-Agora o senhor volte com as suas filhas, discuta com elas e um dia vai entender porque uma composição destas é bonita. Não se envergonhe de perguntar outra vez, porque estou aqui para isto. ${ }^{5}$
\end{abstract}

\title{
Teatros e Cidades sem paredes
}

É preciso esclarecer dois distintos modos de conectar o espaço do teatro com o espaço da cidade: 1) o modo físico que conecta o espaço do edifício teatral tanto com as relações humanas que ali se estabelecem quanto conecta arquitetura cênica com a geografia da cidade; 2) o modo virtual que conecta o ambiente do edifício teatral com o ambiente da cidade, sua urbanidade e humanidades através da tecnologia, de acordo com uma mediação que não admite a presença material de corpos e natureza, mas que, no entanto, cria outras experiências intelectuais, cognitivas e sensíveis através da tecnologia, das múltiplas janelas que podem se abrir nas telas de computadores, tablets e smartphones. Não obstante o modo social através do qual o teatro tradicionalmente se relaciona com a cidade ${ }^{6}$, trataremos nestes estudos especificamente do modo físico e do modo virtual, observados entre as artes da cena e a urbanidade. Cada uma destas modalidades de conexão entre teatro e diferentes cidades, para ser compreendida deve ser investigada separadamente, porém as mesmas podem ser mescladas da mesma forma que uma sala de aula

5 Povo vai ao museu: vê modernos, reage, mas sai gostando. Diário de Notícias, Salvador, 10/11 jan. 1960 apud Pereira, 2007, p. 120.

${ }^{6}$ Conforme bem esclareceu o núcleo de pesquisa da Revista Urdimento, o teatro, através das mídias tradicionais como publicações em jornais e revistas também se relaciona com a cidade no âmbito do espaço social, de acordo com a indústria cultural que se desenvolveu ao longo do século XX, e promove as realizações artísticas conforme um sistema próprio, que se constitui desde a promoção publicitária de artistas às análises críticas feitas por especialistas às realizações nas artes visuais, cênicas, cinematográficas, musicais. 
presencial na Bahia pode ser compartilhada com uma sala de aula virtual que tenha a participação de diferentes estados do Brasil. Antes vamos tecer considerações separadamente sobre os espaços físico e virtual no campo das artes cênicas.

A cenografia, ao se estender ao espaço das cidades, de acordo com o objetivo de um compromisso ético atento à arte em conjunção com a cultura, em conformidade com o discurso de Paulo Freire: "presença consciente no mundo não posso escapar à responsabilidade ética no meu mover-me no mundo" (Freire, 2016, p. 20), observa atentamente os signos erguidos não somente por instituições e governos, mas considera também as expressões populares que se apropriaram de praças e recônditos conferindo novas feições a esses espaços, com o intuito de se envolver, se mesclar com a cidade e adquirir maior possibilidade de colaboração com a produção artística e local, consequentemente promoção de um trânsito de mão dupla entre cidade e teatro. Esse trânsito dinâmico se intensifica quando a cenografia amplia sua atuação para o espaço da docência pois o corpo de estudantes multiplica as investigações espaciais, artísticas e culturais. Certamente a cenografia diretamente voltada para a produção de espetáculos compreende um universo complexo de criação e construção artística, promotora de análises críticas sociais, políticas, culturais e econômicas, porém esta forma de concepção que constrói o espaço nas artes cênicas é a concepção praticada desde os primórdios da cenografia, no entanto, pensar a cenografia como um desbravar das ruas, praças, avenidas, inclusive histórias e culturas da população no entorno do edifício teatral, no contexto de uma prática docente possui o vigor de evidenciar, recriar, reconhecer lugares, realizações artísticas, memórias, artistas que estiveram obscurecidos pelas formas globalizadoras, as quais não comportam as particularidades, pelo contrário, visam tornar homogêneas diferentes comunidades, massificar as populações em defesa de conglomerados empresariais e respectivas mercadorias desvinculadas das

A relação de enriquecimento mútuo entre cenografia e docência foi amplamente analisada e exemplificada na tese de doutorado defendida pela autora deste artigo em abril de 2018, intitulada Helio Eichbauer e Lina Bo Bardi. Artifices que constroem a Arte e edificam a Cidade. Disponível em: http://www.repositoriobc.unirio.br:8080/xmlui/handle/unirio/12889 
singularidades da cultura humana, induzindo indivíduos a consumirem marcas ao invés de comunidades desenvolverem e consumirem a própria cultura.

Esta concepção da cenografia como uma linguagem artística que apreende os diferentes espaços da cidade, os quais envolvem a edificação teatral permitiu considerar a existência de um mecanismo de estruturação, o qual pode dinamizar as relações sociais que existem entre o teatro e a cidade, pois a cenografia ao apreender o espaço urbano que abriga o edifício teatral, produz diferentes análises críticas sobre diferentes espaços da cidade, as quais permitem usos e até mesmo a construção de ambientes mais dinâmicos e humanizados na área citadina, que propiciem a expressão comunitária em diferentes localidades, a valorização de diferentes artistas e de suas obras, possivelmente excluídos da visibilidade globalizante, artistas que no entanto, produzem a cor local, enriquecem artisticamente o cotidiano de recônditos e praças.

É importante informar que esta promoção da cidade também foi empreendida no contexto de docência da cenografia, no entanto esta relação com o ensino e a aprendizagem será averiguada mais detalhadamente em estudos subsequentes. Destacam-se aqui unicamente as questões técnicas que foram observadas, as quais tratam do estudo dos diferentes espaços da cidade, e que constitui uma forma de apropriação cognitiva e criativa destas localidades. Tratase de estudar e conhecer os espaços oficiais, conhecer e colher registros dos espaços apropriados pela população para realizações artísticas, conhecer e decodificar os signos históricos da cidade, conhecer e projetar a cenografia urbana erigida pela cultura local através da docência.

Também é importante esclarecer que foram verificadas questões éticas relacionadas à proximidade que existe entre teatro, universidade e âmbito artístico e cultural da cidade, cujos habitantes são os que possivelmente assistirão em maior número as produções artísticas locais, e mesmo devem integrar as concepções artísticas e culturais, de acordo com o entendimento de que "Não podemos nos assumir como sujeitos da procura, da decisão, da ruptura, da opção, como sujeitos históricos, transformadores, a não ser assumindo-nos como sujeitos éticos." (Freire, 2016, p. 19). 


\section{A apropriação do teatro pelos construtores da cena}

Diretamente relacionada a esta conexão, que conjuga os estudos e projetos cenográficos ao espaço da cidade que abriga o edifício teatral, está a consideração a respeito dos trabalhadores e trabalhadoras que empreendem atividades fabris nos mais diversos campos, desde a marcenaria a pintura de tecidos, do corte e costura a serralheria. Neste conjunto de profissionais, estão possíveis colaboradores com a construção de cenografias e indumentárias, pois os projetos técnicos de construção de cenografia, indumentária e iluminação se concretizam através de profissionais que têm a habilidade técnica e construtiva. A partir desta consideração tanto verificações éticas quanto sociais e culturais podem ser discriminadas.

Em relação à ética, é preciso atentar para o fato de que a cena teatral se constrói entre realizadores e espectadores, porém uma separação entre estes dois grupos se agigantou acompanhando os modos de vida compartimentados embasados pelo modo de vida demandado pela sociedade capitalista. Para cada classe, um tipo de consumo, inclusive um tipo de consumo de acordo com a indústria cultural. A partir da segunda metade do século XX, ao se desenvolverem amplamente os canais de comunicação como as redes de televisão e rádio, inclusive cinemas, o teatro não somente teve que dividir seu público com estes novos meios de entretenimento como adquiriu feições de uma forma de arte elitista e de formato restritivo, separado das ruas e praças, espaços naturalmente democráticos. E a própria classe artística contestou o edifício teatral, distinguindo tanto uma severa separação entre cena e plateia quanto questionando acirradamente a estrutura fechada dos edifícios teatrais, que potencializam a distância entre a arte e o espectador. Mas será que tais apontamentos desfavoráveis aos edifícios teatrais não obscureceram outras formas de usos e compreensão desta arquitetura? E com relação aos trabalhadores nestes edifícios como os eletricistas, as camareiras, os técnicos especialistas responsáveis pela manutenção de equipamentos e diferentes aparatos desses edifícios? Como este contingente humano foi considerado ou não foi considerado? 
A Revolução Industrial retirou do conjunto de trabalhadores artífices o poder de gerir sua própria força de trabalho, e o sistema capitalista afirmou esta espécie de mutilação da cultura e da humanidade ${ }^{8}$. A desumanização que se seguiu neste contexto de escala global de produção e consumo evidenciou a importância de realizarmos uma revisão a respeito das formas de trabalho e dos produtos e serviços comercializados. Similarmente os edifícios teatrais foram atingidos por este processo de desumanização e necessitam de novos olhares sobre suas realizações artísticas e profissionais, bem como revisão de suas atribuições.

A respeito das relações de trabalho realizadas nos edifícios teatrais, o cenógrafo e professor Helio Eichbauer deu o seguinte parecer:

O chefe do setor de iluminação do Teatro Municipal do Rio de Janeiro era o médico do teatro José Bertelli Sobrinho; um grande inventor da arte cênica, com larga experiência na área desde os anos de 1950. Viu tudo de bom, participou de montagens antológicas e morreu discretamente, sem ter gravado seu depoimento para as futuras gerações. A direção do teatro, que não se importava muito com aquele "velho ranzinza", nunca prestou as homenagens que ele merecia. As pessoas também são patrimônio histórico. Bertelli tinha belas histórias para contar, que foram enterradas com ele .

Este relato do cenógrafo Helio Eichbauer, que realizou uma obra extensa no campo das artes cênicas desde a década de 1960, e não somente no Brasil, mas também no exterior, que também teve diferentes realizações analisadas por críticos e historiadores do teatro, evidencia uma lacuna no campo das atividades realizadas no espaço dos edifícios teatrais, que trata dos aprimoramentos técnicos, que trabalhadores realizam para que as produções artísticas teatrais alcancem êxito nesta complexa máquina que é a caixa cênica italiana. Ao

\footnotetext{
${ }^{8}$ A diversidade dos padrões culturais, dos objetos e dos hábitos de consumo é um fator de perturbação intolerável para as necessidades da expansão constante que é intrínseca ao capitalismo. As diferentes modalidades da produção cultural (da burguesia e do proletariado, do campo e da cidade) são reunidas, e até certo ponto homogeneizadas, devido à absorção, num único sistema, de todas as formas de produção (manual e industrial, rural e urbana)... se cria a ilusão de que todos podem desfrutar, real ou virtualmente, da superioridade da cultura dominante. Qualquer desenvolvimento autônomo ou alternativo por parte das culturas subalternas é impedido, tanto o seu consumo e produção quanto a sua estrutura social e linguagem são reordenados com a finalidade de se tornarem adaptados ao desenvolvimento capitalista. (Canclini, 1983, p. 27).
}

${ }^{9}$ Eichbauer, 2013, p. 47 
considerar o ensino da cenografia e indumentária sem abordar a atuação conjunta dos cenógrafos e figurinistas com serralheiros, carpinteiros, costureiras, uma lamentável falta de compromisso ético com estes trabalhadores pode ser configurada. E estes trabalhadores, assim como todos os demais profissionais que atuam nos teatros, e toda plateia residem no espaço das cidades que se relacionam com os diversos edifícios teatrais, os quais compõem a arte e a cultura de diversas regiões. Existe um trafegar do interior para o exterior e vice-versa que leva e traz culturas e humanidades. Justamente este intercâmbio precisa ser investigado e valorizado, pois ele vivifica o edifício teatral e contesta a crítica negativa que diz que este edifício impõe barreiras ao acesso da população, o que o discrimina como antidemocrático. É preciso considerar que não é a arquitetura teatral que impõe barreira à plena fruição das apresentações teatrais, mas sim as hierarquias nas relações humanas e profissionais promovidas pelo modo de vida capitalista, o qual seguimos irrefletidamente, até mesmo promovendo críticas que, no caso dos edifícios teatrais, podem configurar um equivocado descarte de um equipamento cultural com grande potencial para promoção das relações humanas.

A cidade que abriga o edifício teatral possui uma cultura própria no cerne da qual se distinguem artistas e artífices. É preciso considerar a promoção da conexão entre estes artistas e artífices com o edifício teatral, inclusive se forem diversos edifícios, para que a população local se aproprie do espaço teatral de sua cidade desde a construção do fazer teatral. A promoção desta conexão pode ser realizada a partir dos próprios edifícios teatrais.

\section{A Tecnologia da Informação e Comunicação na interface entre o teatro e a cidade}

Diante do atual contexto de contaminação letal que caracteriza a doença infecciosa Covid-19, exigindo temporariamente distanciamento social, afastamento dos espaços públicos das cidades bem como suspensão das atividades realizadas em ambientes fechados como teatros, cinemas, museus, 
bares, o ciberespaço ganhou relevância vital, e o aprendizado e experimentação em seus domínios foram repentinamente acessados pelas diferentes práticas no campo da linguagem teatral. É preciso considerar que a realização cênica que empreende o ciberespaço é uma prática que se experimenta desde finais da década de 1950. Os estudos de Béatrice Picon-Vallin intitulados Jacques Polieri na História das Artes do Espetáculo (Picon-Vallin, 2008, p. 99-111) conferem importante análise histórica a respeito do uso de projeções "no âmbito de uma cena planetária, cyber-teatro." (Picon-Vallin, 2008, p. 100).

A respeito do estudo sobre a inclusão de imagens projetadas na cena teatral a autora aborda as realizações não somente do francês Jacques Polieri como também as práticas do tcheco Josef Svoboda, então considerados como cenógrafos que em meados do século XX empreenderam o aprimoramento das mídias de tecnologia cinematográfica e virtuais nas artes cênicas, porém, segundo as análises de Picon-Vallin, as particularidades da obra de cada um destes criadores, bem como semelhanças e diferenças entre ambos, ainda não foram devidamente investigadas. Certamente estas análises conferirão subsídios para novas propostas que reúnam projeções e espaço virtual, porém o objetivo dos estudos aqui apresentados a respeito dessa conjunção no contexto da expressão teatral é a de atentar para a conexão virtual do espaço da caixa cênica com o espaço das ruas, avenidas e praças adjacentes, que promova um atento olhar sobre a cidade, especificamente olhar analítico sobre o entorno da cidade que abriga o teatro, pois este olhar está de acordo com os estudos propostos neste artigo que tratam da aproximação do edifício teatral com a cidade e seus habitantes, promovendo o trânsito de mão-dupla entre teatro e cidade.

Polieri trata de "novos espaços-tempos híbridos" (Picon-Vallin ,2008, p. 110), possibilitados por uma tecnologia digital grandiosa que ao dispor da internet, dialoga com um novo espectador capaz de absorver múltiplas visões e sentidos, como as personagens multifacetadas do cubismo de Picasso, a que se referiu Picon-Vallin ao tratar da maneira como Svoboda compôs uma cena multifacetada composta por múltiplas telas de projeção. A multiplicidade do espaço cênico a partir das tecnologias de projeção e manipulação do espaço virtual, portanto, já 
confere estudos históricos que permitem fundamentos à prática teatral, mas podemos considerar outro ponto de vista acerca do espaço, que a condição de reclusão imposta pela contaminação virótica pôde iluminar: a visão estendida desde o espaço cênico cúbico às ruas e avenidas adjacentes aos teatros para que os edifícios teatrais sejam ainda mais apropriados pelo seu entorno social.

O Google Maps é uma ferramenta de localização geográfica muito acessada na contemporaneidade por quem deseja não somente saber trajetórias, mas também ver o espaço físico através do transitar no espaço virtual. Podemos considerar que tal ferramenta possibilite, através da concepção teatral um olhar crítico sobre o entorno dos teatros. Certamente é possível desbravar locais inimagináveis através do Maps, mas observar criticamente o espaço que nos abraça e perceber identidades, atentar para descuidos com a natureza, dialogar com a cultura local está no cerne da proposta de "espacializar os conhecimentos" (Foucault, 2007, p. 52). Através das plataformas e programas que as tecnologias de informação e comunicação permitem, estudiosos do espaço teatral podem promover esta aproximação do espaço cênico com o espaço da cidade. A apropriação artística de tais tecnologias não é simples, certamente, exige tempo de aprendizado e experimentação, porém também se faz necessário pensar o motivo de tal apropriação, o objetivo que temos ao alçar o espaço virtual. A condição temporária de isolamento pode ser percebida como motivação para o uso dessas tecnologias, mas não devemos perder de vista a humanidade que constitui a arte teatral. A respeito do uso de novas tecnologias relacionadas ao teatro podemos considerar as práticas de Josef Svoboda:

[...] Sua paixão pela civilização mecânica contemporânea, pelos novos materiais, pelas invenções no campo da iluminação, da comunicação e do movimento, nunca o fez perder de vista o elemento humano. Ele se interessa, antes de tudo, pela influência da irrupção técnico-científica de nosso tempo sobre o homem. Ele compreende e honra o humanismo, a cultura e o peso filosófico do tecnicismo de hoje, mas vê sua crueldade, sua demência e seu horror... para ele, o valor fundamental reside nas relações humanas e na capacidade que o talento artístico possui de criar uma nova realidade autêntica. ${ }^{10}$

${ }^{10}$ Citado por Denis Bablet, em Josef Svoboda, Lausanne: L’Age d'Homme, nova edição, 2004, p. 160, apud Picon-Vallin, 2008, p. 107. 
Portanto, duas formas de construção e análise crítica do espaço foram investigadas no âmbito da Cenografia: 1) a construção do espaço cênico que se amplia ao espaço urbano da cidade que abriga o teatro, e que, portanto, compreende a colaboração dos artífices e técnicos, e respectivas relações humanas que neste âmbito se constroem; 2) a apropriação do espaço urbano que envolve o edifício teatral através das plataformas virtuais, como o Google Maps, que permite o desbravamento de ruas e avenidas sem deslocamento físico.

É preciso considerar que ainda que não haja a presença e vivência do espaço, análises críticas e artísticas podem ser feitas com o auxílio das plataformas digitais, que possibilitem singular realização artística teatral. Portanto, a partir destas duas formas de construção e análise da Cenografia, podemos pensar a proposta do espaço cênico teatral como um espaço integrado à cidade. E com o auxílio das ferramentas de tecnologia de informação e comunicação podemos promover um olhar crítico sobre as ruas, praças, avenidas, bem como promover identidade cultural e consciência urbana e ambiental em conformidade com diferentes linguagens artísticas.

Ao longo da história da humanidade homens e mulheres edificaram cidades através das artes e dos ofícios e estes sempre desenvolveram diferentes tecnologias. A tecnologia de informação e comunicação é mais uma tecnologia no contexto de vida do ser humano, que se encontra em permanente processo de aprimoramentos. A humanidade reside justamente nessa ação de poder criar através das tecnologias, portanto, que o teatro e as cidades sejam apropriados pela humanidade que subjaz às diferentes tecnologias.

\section{Referências}

CANCLINI, Néstor García. As culturas populares no capitalismo. Trad. Cláudio Novaes Pinto Coelho. São Paulo: Editora Brasiliense. 1983.

EICHBAUER, Helio. Cartas de marear: Impressões de viagem, caminhos de criação. Rio de Janeiro: Casa da Palavra, 2013. 
EICHBAUER, Helio. A musa urbana: os coretos da cidade. In: 2a Jornada Nacional Arquitetura, Teatro e Cultura, 2014. Caderno de resumos da 2a Jornada Nacional Arquitetura, Teatro e Cultura. Universidade Federal do Estado do Rio de Janeiro/Laboratório de Estudos do Espaço Teatral e Memória Urbana, p. 46 e 47. Disponível em: http://www.unirio.br/espacoteatral/arquivos/publicacoes/pdfpublicacoes/caderno-resumos-jornada-2014.pdf Acesso em: 30 jun. 2020.

FOUCAULT, Michel. As palavras e as coisas: uma arqueologia das ciências humanas. Trad. Salma Tannus Muchail. 9ạ ed. São Paulo: Martins Fontes, 2007. (Coleção Tópicos).

FREIRE, Paulo. Pedagogia da Autonomia: saberes necessários à prática educativa. 54a ed. Rio de Janeiro: Paz e Terra, 2016.

PEREIRA, Juliano Aparecido. A ação cultural de Lina Bo Bardi na Bahia e no Nordeste (1958-1964). Uberlândia: EDUFU, 2007.

PEREIRA, Regilan Deusamar Barbosa Pereira. A humanidade da caixa cênica italiana de acordo com o discurso do cenógrafo e professor Helio Eichbauer. In: X Reunião Científica ABRACE, 2019. Anais da X Reunião Científica da Associação Brasileira de Pesquisa e Pós-Graduação em Artes Cênicas, Campinas, p. 1-18.

PEREIRA, Regilan Deusamar Barbosa Pereira. Helio Eichbauer e Lina Bo Bardi: artífices que constroem a arte e edificam a cidade. Rio de Janeiro, 2018. Tese (Doutorado) - Programa de Pós-Graduação em Artes Cênicas - PPGAC. UNIRIO, Universidade Federal do Estado do Rio de Janeiro.

PICON-VALLIN, Béatrice. Jacques Polieri na História das Artes do Espetáculo. In: PICON-VALLIN, Béatrice. A cena em ensaios. Trad. Fátima Saadi, Cláudia Fares e Eloisa Araújo Ribeiro. São Paulo: Perspectiva, 2008, (Coleção estudos; 260), p.99 a 111.

Recebido em: 30/06/2020

Aprovado em: 01/08/2020 